\title{
ALGUNAS VERSIONES DE PROGNE Y FILOMENA
}

\author{
JosÉ FRADEJAS LEBRERO \\ Instituto de Estudios Madrileños-UNED
}

El desarrollo de estas narraciones conforma un típico motivo folklórico -T 425: El cuñado seduce a su cuñada- que inmediatamente sugiere, por su desarrollo, a Ovidio ${ }^{1}$. Estamos, pues, en un caso de literaturización de una narración folclórica que ha sufrido los siguientes pasos: 1. literaturización o desfolclorización (Ovidio); 2. folclorización (Relación y Romancero); y 3. nueva literaturalización o desfolclorización (Pedro de la Sierra y Pero Sánchez). Veamos su evolución histórico-literaria.

En Roma, Ovidio y Antonino Liberalis (siglo II) nos dieron dos versiones: Progne y Aenone, respectivamente, y el primero fue famosísimo en la Edad Media. Recordamos que Alfonso X llama a las Metamorfosis ovidianas su «libro mayor» y las utiliza - a través de alguna glosa- en la Grande e General Estoria: Jueces, caps. CXXVIII a CXLVII. Es una ampliación novelesca que sigue a Ovidio, pero con un gran desarrollo literario. Se podría decir que es una novela mitológica medieval. Pero como la obra alfonsina permaneció inédita, no hay duda, pues, de que fue inane para el desarrollo posterior.

Su evolución parte de los estudios humanísticos del Renacimiento. Cuántos y cuántos estudiantes de los siglos medios leyeron a Ovidio - recuérdese el estudio de Shevill ${ }^{2}$ - ; y cuántos y cuántos profesores de latín tradujeron con sus alumnos las Metamorfosis ${ }^{3}$.

Es indudable que tantos y tantos estudiantes, y también lectores, de Ovidio tuvieron la oportunidad de crear imitando multitud de obras basadas en sus le-

\footnotetext{
${ }^{1}$ Ovidio, Metamorfosis, Libro VI: Progne y Philomena.

${ }^{2}$ Rudolph Schevill, Ovid and the Renaissance in Spain, Berkeley, California University Press, 1913.

${ }^{3}$ Cfr. Marcelino Menéndez Pelayo, Bibliografía hispano-latina clásica, 10 vols., Santander, CSIC-Aldus, 1950-1953, t. VII, págs. 180-333.
} 
yendas, especialmente las más novelescas, como esta de Progne y Philomela (recuérdese Juan Rodríguez de Padrón, en el siglo XV). Y así, vamos a enumerar lo que en la obra del señor A. M. Martín Rodríguez falta:

Todavía será utilizado episódicamente por Juan Bautista Diamante en su obra Júpiter y Semele 5 y una Tonadilla del siglo XVIII, Progne y Filomena, de Caballero del Pozo cuyo manuscrito se conserva en la Biblioteca Municipal de Madrid. Una traducción abreviada y en prosa incluye el P. Pineda en sus Diálogos de la Agricultura Cristiana (1589). Más desconocida es esta relación de Matías Escudero de Cobeña ${ }^{6}$.

El suceso ocurrió en el pueblo de Alcoboso en 1576; puede que haya sucedido realmente, pero el paralelismo con nuestro tema es tan fiel que uno duda si lo comparamos al episodio de Julieta y Romeo ocurrido los días 20 y 23 de enero de 1999 en Maracena y Cijuela (Granada), entre María Águeda y David ${ }^{7}$. Estos sucesos nos ponen en guardia para no afirmar, taxativamente, una derivación ovidiana y tratar el tema con cierta cautela a pesar de las concomitancias.

Un nuevo desarrollo, en un país exótico, Cimarra (África), entre príncipes paganos nos da un cierto aire de cuento o novela trágico-moral, pues hasta se simplifica el sentido brutal: no hay ofensa sexual, sólo asesinato. ¿O justificación moral de la asaltada?

La primera versión de esta leyenda, muy dulcificada, es obra de Pedro de la Sierra, infanzón natural de Cariñena, que la incluyó en su Espejo de Príncipes y Caballeros $^{8}$. Trata de los altos hechos del Emperador Trebacio y sus caros hijos y es la segunda parte de la obra de Diego Ortúñez de Calahorra, natural de Nájera, con el mismo título, pero también conocida por Caballero del Febo y su hermano Rosicler 9 .

Se incluye esta narración en el capítulo XII, y siendo como es imitación de la leyenda mitológica de Progne y Filomela, se singulariza por varias razones: 1) se duda si hubo estupro o no; 2) no existe transformación en aves, luego se cristianiza — no obstante el recuerdo a los «inmorales» dioses- en cierta medida; 3) se narra en primera persona con apelaciones al «caballero que a ver y poder leer esto alcançares».

\footnotetext{
${ }^{4}$ Antonio M. ${ }^{a}$ Martín Rodríguez, De Aedón a Filomela. Génesis, sentido y comentario de la versión ovidiana del mito, Las Palmas de Gran Canaria, Universidad de las Palmas, 2002.

5 Juan Bautista Diamante, Comedias, Madrid, Andrés García de la Iglesia, 1670, págs. 89112, pág. 102.

${ }^{6}$ Matías Escudero de Cobeña, Relación de cosas notables, ed. Fernández Izquierdo, Guadalajara, Ayuntamiento de Almonacid de Zorita, 1982.

${ }^{7}$ ABC, 26-1-1999, pág. 84.

${ }^{8}$ Pedro de la Sierra, Espejo de Príncipes y Caballeros, Alcalá, Juan Íñiguez de Lequerica, 1580.

${ }^{9}$ Diego Ortúñez de Calahorra, Caballero del Febo y su hermano Rosicler, Alcalá, Juan Íñiguez de Lequerica, 1580.
} 
Pero Sánchez, y no Pedro Sánchez, que es un homónimo contemporáneo y jesuita, fue racionero de la Catedral de Toledo y algún tiempo Rector del Hospital del Nuncio.

Fue autor de tres libros interesantes. El que ahora nos interesa es Triángulo de las tres virtudes teológicas ${ }^{10}$.

La muerte de una infanta es una imitación de la de Pedro de la Sierra, pues al margen dice Yspejo de Príncipes, $2^{a}$ parte, Capítulo 12. Hay notables diferencias en esta imitación como se observa, sobre todo, en la interpretación moral del hecho apoyándose en P. Palude y, sobre todo, en el Florentino, San Antonino de Florencia.

La consecuencia para Pero Sánchez es la fuerza moral y la inocencia de la infanta en el caso de haber sido forzada y su valoración en el supuesto que fuera cristiana. Se sigue, pues, en cierta medida la moralización de Bellero:

En la transformación de Philomena en Ruyseñor se da a entender que, quanto más el vicio procura opprimir la virtud, tanto más ella se ensalça, y da a conocer su suavidad, pues habiendo Tereo privado a Philomena de la lengua porque no descubriesse su maldad, la dotó el cielo del más suave, dulce y deleitoso canto que se puede oir entre las aves ${ }^{11}$.

No conozco en esta evolución ninguna otra narración derivada; hubo, eso sí, un intento novelesco repetidamente anunciado por aquel judío de Espejo (Córdoba), genio de la Economía que, exiliado en Holanda en el siglo XVII, José de la Vega (por otros conocido por José Penso de la Vega), intentó escribir, pero no la llevó a efecto, una novela: Progne y Filomena.

Los dos textos en verso, uno: Filomela de San Buenaventura es un poema místico muy poco conocido que López de Úbeda incluyó en su Cancionero $^{12}$; y Cancionero general de la Doctrina Cristiana ${ }^{13}$. Por su extensión, sólo doy el índice de los doce cantos. Lo había en parte publicado Fray Luis de Granada, al final del Memorial de la Vida Cristiana (1563) en Obras $^{14}$. Preámbulo sobre la Philomena de San Buenaventura, que aquí se añadió y que se reeditó en Cruz y Raya en 1935. Bien es verdad que consta de un breve preámbulo en prosa y una selección de versos significativos.

El segundo texto es hispano-americano, aunque su autor fuera español, y es una tardía Defensa de las damas, fue publicado en Lima, 1603, que por su ra-

\footnotetext{
${ }^{10}$ Pero Sánchez, Triángulo de las virtudes teológicas, Toledo, 1595.

11 Madrid, BNE, ms. 8927.

${ }^{12}$ López de Úbeda, Cancionero general de la Doctrina Cristiana... con otras muchas obras recogidas de muy graves autores, Alcalá de Henares, Juan Íñiguez de Lequerica imp., 1579.

${ }^{13}$ Cancionero general de la doctrina cristiana, ed. Rodríguez-Moñino, 2 vols., Madrid, SBE, 1962-1964, t. II, págs. 154-193.

14 Obras, tomo III, Madrid, Pedro Marín imp., 1788, págs. 583-586.
} 
reza traemos a cuenta, ya que Pilar Oñate en El Feminismo en la Literatura Española $^{15}$ ni ningún otro tratadista del tema parece ser que lo recuerdan.

\section{I}

MATÍAS ESCUdERO DE COBEÑA, Relación de casos notables ocurridos en la Alcarria y otros lugares en el s. XVI, ed. Fernández Izquierdo, Guadalajara, Ayuntamiento de Zorita, 1982. Transcripción y selección de F. Fernández Izquierdo.

CAPÍtulo 766: De un extraño caso que sucedió en la villa de Alcoboso, que es en Cataluña, en el Condado de Barcelona, a un mercader (págs. 224-227).

Entre otras cosas que sucedieron el año de mil y quinientos y setenta y seis, contaré esta que sucedió al principio del mes de noviembre, lo cual sea para ejemplo y aviso de todos los que esto leyeren, o oyeren, para que se sepan guardar y librar de las malas obras y malos pensamientos que el demonio a los hombres les convida y atrae con ponerles delante, que no se sabrá.

El [sic, en] la villa de Alcoboso, que es un condado de Barcelona en Catalunia, había un mercader mancebo y rico, y de muy buena gracia, que se decía Juan Bara. El cual, con la fama de sus riquezas, y buena gracia de su persona, y de ser hombre muy aplicado, vino a casar con una hija de un cibdadano de Barcelona muy rico y honrado. Hay desde Barcelona a la villa de Alcoboso veinte leguas. Y como fue casado, llevóse a su mujer y casa, a do vivían. Y como había ya dos años que estaban casados, los padres de la recién casada tenían otra hija, hermosa y de muy buena gracia, doncella. La cual parece que le dio afición y gana de ver a su hermana, por quererse las dos muncho. Los padres, como no entendieron el afición que su hija tenía por ver a su hermana, por darle contento, por lo muncho que la querían, ordenaron de que la fuese a ver. Y como supieron los padres que en la villa de Alcoboso se hacían ciertas fiestas, acordaron que fuese la doncella para estonces. Y así fueron con la doncella desde Barcelona dos primos hermanos suyos, con sus criados.

Llegados allá, fueron muy bien recebidos de la hermana, y de su marido. Llevaban orden desde Barcelona de los padres de la doncella que, pasados los tres días de las fiestas, luego se viniesen. Como iban sin hacer otra cosa, pasadas las fiestas, luego los primos hermanos dijeron que se querían volver a Barcelona con la doncella, y la doncella holgaba dello, por hacer 1o que sus padres le mandaron. El cuñado casado con la hermana estuvo tan porfiado e importuno con los primos y con la doncella, que no dio lugar a que la doncella se fuese, sino que había de quedar con su hermana unos días, y después la llevaría a Barcelona. Y así, se quedó la doncella en casa de su cuñado, y los mancebos se fueron a Barcelona, y dijeron a su padre cómo no bastó razón con su yerno para dejársela traer. A los padres parece que les pesó dello, aunque estaba con su hermana.

El Juan de Bara, con poco temor de Dios, lleno el corazón de maldad, con deseos carnales, puso los ojos en la doncella hermana de su mujer. El cual, aguardando tiempo

\footnotetext{
${ }^{15}$ Pilar Oñate y Pérez, El feminismo en la literatura española, Madrid, Espasa-Calpe, 1938.
} 
oportuno, le declaró a la doncella sus malos deseos carnales. Ella, como doncella muy honesta y noble, siendo muy buena cristiana temerosa de Dios y guardadora de su honra, no quería dar oídos a tal cosa; antes invocaba el auxilio y socorro de Dios y de Nuestra Señora. Y le dijo: «Señor, no trates de tal cosa, que no hay para qué», y otras palabras ansí en su defensa. Y de que [= cuando] él vido cómo no le aprovechaban sus palabras, y que ella con ellas también se excusaba y defendía dél, púsose él en importunarla con las obras, quiriendo hacerle fuerza. Pero ella le defendió, como buena mujer. Y como mujer cuerda, guardó el secreto, por no dar pena a su hermana y a otros.

El cuñado andaba siempre cada día buscando medios para ejecutar su mala intinción, y por cumplirla, ordenó una traición y maldad desta manera:

Llama en secreto a un pajecillo, persona que no entendiese bien lo que escribiese, y le escribió una carta como que venía de Barcelona, diciendo cómo su madre la escrebía, y le enviaba a decir: «Hija mía, vista ésta, luego otro día [al día siguiente] como ésta os llegue, os partiréis con vuestro cuñado Juan Bara, porque sabe que yo quedo muy mala, y antes que yo muriese, holgaría de os ver». Y traía de porte la carta dos reales. Y viene el Juan Bara, dala a un forastero, a el cual le dijo cómo la llevase a casa de Juan Bara, y dijese cómo el venía de Barcelona, y cómo le encomendaron que diese aquella carta, y cómo él vido a su madre en la cama mala. Y así, el forastero fue con su carta, lleno de polvo, a casa de Juan Bara, y pidió los dos reales a las dos hermanas, y dijo y fingió todo lo que se le había encomendado que dijese. Y como las dos hermanas leyeron la carta, comenzaron a llorar. Y a cabo de buen rato, vino el Juan Bara, y como las halló a entramas llorando: «¿Qué es esto, que entramas lloráis? Decidme la causa dello». Y ellas dícenle: «Sabe que un forastero nos ha dado una carta de Barcelona, y dice cómo está muy mala nuestra madre, o será muerta, o está para ello. La cual podéis ver». Y como la hubo leído, comienza a fingir la pena que dello tenía, y díjole a la doncella: «Señora hermana, lo que conviene es que partamos vos e yo luego sin dilación, a un negocio como este». La doncella temíase, y no quería ir con él, por la sospecha que dél tenía. La hermana casada decía: «Hermana, ¿qué dudaís?, e asús [sic, salte] presto de aquí, mira lo que importa, que con mi marido bien segura y guardada irés».

El marido, con diligencia aderezó la partida, y no quiso llevar compañía consigo, como iba fundado en hacer mal, como lo hizo. Y como ovieron caminado las seis leguas, llegaron a una floresta, y viene, y hace a la mula en que iba la doncella, que dejase el camino real, y métela por una senda abajo, la cual era senda perdida. Y como él vido que estaban apartados del concurso de la gente, apeose él, y díjole a la doncella: «Entended, hermana, que vuestro amor me trae muerto, y muero por vos. Y pues estamos a do nadie no parece, ni nos vee, cumplí [sic, cumplid] mi voluntad y deseo». Y la doncella, visto la gran villanía que con ella quería usar, deciende de la mula de presto, y dice que tal no consentiría. Y como el cuñado vido que no aprovechaban palabras, arremete a ella, y comienza a luchar con ella, para hacerle fuerza. Y con ella no pudo, porque se le defendió. Visto él que no aprovechaba con ella, echó mano de una daga contra ella, para si no venía en lo que él quería, y ella se desvió, y echó mano a una piedra, y se la tiró, y le dió en la cabeza, que lo descalabró. Y él estonces arremete a ella, y diole con la daga tres heridas, y diole luego un tan grande empellón y golpe, que dio con ella en el suelo, y la aturdió. Y luego, sin temor de Dios, della se aprovechó, estando ella con tres heridas y aturdida, y casi muerta. Y estaba tal, que casi la 
fuerza que se le hizo no sintió. Y habiendo cumplido su voluntad con ella, dejarretó la mula en que iba ella, y se la dejó allí cerca la mula della, y él volviose a su casa herido y escandalizado de lo que había hecho. Y en llegando a su casa, comenzó a decir que habían salido a él y su cuñada treinta ladrones bandoleros, y por defender a su cuñada, le habían a él herido y maltratado, y a ella que la habían herido, y dejarretado la mula, y que ya sería muerta. Y la mujer, llorando por su hermana, por lo que había dicho su marido, ordenó luego de llamar a un zurujano [sic, cirujano] para curar a su marido, y le echó en su cama, y lo curaron bien. Y él, estando en la cama, acordándose de lo [que] había hecho, sospiraba muncho. Y díjole la mujer: «¿qué es esto que tanto os veo sospirar?». Dijo él: «No queréis que tenga pena, pues la ternán [= tendrán] vuestros padres de que [= cuando] sepan el caso tan desastrado de su hija? Y asímismo, me parece, mujer, que será bien levantarme yo de la cama como pudiere, y llevaré seis hombres comigo, y haré información cómo llevaba muy honestamente a vuestra hermana, y de lo que me sucedió. Y a ella la traeremos a enterrar».

La doncella, como quedó en el suelo herida de tres heridas, y maltratada de los golpes que le había dado, y como se desangraba, llama con voces a Dios, y a Santa María de la Concepción, de quien ella era muy abogada [= devota], que la quisiese socorrer en aquella tribulación en que estaba, y recibiese su ánima, que tan cercana estaba a la muerte. Y decía otras grandes lástimas con grandes gemidos, que a cualquiera que la oyera, quebraba el corazón. En esto, sucedió que a un ganadero se le habían perdido unas vacas en aquel bosque, y andando buscando las vacas, oyó las voces de la doncella, y los lloros y gemidos que daba. Y en rastro dellos, fue a parar a do la doncella estaba herida y maltratada. El cual, de que [= cuando] la vido, preguntó que quién la había tan malparado, o quién la había a ella traído allí. Y ella, como lo oyó a este hombre, probó a levantarse, y no pudo. Y al punto, este hombre va con diligencia a sus ganados, y trae cuatro pastores, y llevaron a la doncella a su casa, como mejor pudieron. Y luego la hizo curar lo mejor que supo. Y ella pidió luego confesión, y se la dio la comunión. Y pidio tinta y papel, y como mejor pudo, escribió a su hermana todo el negocio de la traición como pasó. Y el ganadero, con un su pastor, envió la carta a su hermana. Y cuando el pastor llegó con la carta, su marido había ido a buscar a su cuñada, para traerla a enterrar, y llevaba seis hombres, para hacer información para su descargo. Y como la mujer por la carta vido la grande traición de su marido había hecho con su hermana, determinó de matar un hijo que tenía de su marido, de seis meses, y pone asar la mitad, y la otra mitad, hizo un guisadillo. Y como el marido vino, y dijo cómo no había hallado a su cuñada, pidió la cena, y díjole (la mujer): «Asentáos». Y diole lo asado a comer, y dijo: «Come, que carne tierna [?] es». Y el marido pidió por el hijo, y dijo ella: «Come de esotra, que en casa de su ... [borrado] está el niño, y luego, lo traéran». Y luego saca ella en la mano la cabeza del niño, y en la otra mano un destral, y le puso encima la mesa la cabeza, y dícele: «Pues mataste a mi hermana, y la forzaste, justo es que lo pagues», y diole con el destral en la cabeza, y lo mató. Y como la moza de casa lo vida matar, comenzó a dar voces, y porque no quiso callar, la mató con el destral.

Los vecinos, a el ruido, acudieron, y la justicia, y ella contó todo como pasó. Y desde allí la sacaron a justiciar. La tenazaron, y la ahorcaron, y la descuartizaron. Sacáronla a justiciar desde su casa. 
Pedro DE LA Sierra, Espejo de Príncipes y Caballeros, Alcalá de Henares, 1580, fols. 27 (errado 29)-29b.

CAPÍTULO XII: De cómo el emperador abrió el pergamino, y leyó la causa porque la difunta señora avía sido muerta de aquellas tyranías, y la lástima que dello el Emperador sintió.

Hermosas damas, de que algunos sin conoscimiento de vuestro merecer, toman osadía con sus venenosas palabras, y emponçoñada pluma, mal tratar vuestras honras, publicando mal, lo que con justa razón, y aun obligación, avían de defender, y amparar: y los caualleros están obligados de los semejantes detractores libraros, o con fuerça de armas, o con argumentos concluyentes: suplico a vuestra belleza perdoneys a mi demasiado atrevimiento, pues que me pongo a dezir lo que tan entendido de todos avía y devía estar de vuestra lealtad y firmeza, teniendo por espejo esta hermosa dama, que tan no merecida muerte padesció, qual el Emperador en el castillo vio, de que se os ha contado, que debaxo del almohada un pergamino sacó arrollado. Abierto que uvo el Emperador el pergamino, le leyó, y vio que assi dezia.

Yo el triste Rey de Cimarra, en otro tiempo harto favorecido de la ocasión que a ser señor de tan grande estado me truxo, con gozar de dos hijas, las más hermosas que naturaleza formar pudo. Trúxome a tal tiempo, que lo que más contento me causava, esso mesmo me vino a dar el mayor tormento, que hombre humano sufrir pudo.

Mis dos hijas fueron dotadas de estremada belleza, acompañadas de la honestidad que a su estado convenía: a cuya fama mi corte fue poblada de los Príncipes, y señores de todo el mundo, en especial de los Africanos: tanto, que vino a ser la más noble Corte que Rey tuvo, unos por venir a ver la flor de cavallería, otros codiciando casar con mis dos hijas. Entre los quales fue preso de amor (aunque en ausencia, solo por la fama de su hermosura) Noraldino, Rey de Numidia, tan poderoso como falso: el qual me embió sus embaxadores, para que tuviesse por bien de le dar la una de mis hijas por muger: yo considerando, que en ello antes se aventurava gran honra, y fama, por conoscer su grandeza, y no sus trayciones, tuve por bien de condecender con su embaxada, y voluntad. Concertáronse los casamientos con la mayor, la qual fue llevada con gran pompa y aparato, según a su estado y al mío convenía, al Reyno de Numidia. Quedeme yo acompañado de la menor, que Herea se llamava, en estremo más hermosa que su hermana: de lo qual fue informado el traydor y desleal Rey de los suyos, que al acompañamiento de mi hija embió. Tanto se lo encarescieron, que sin auer en la resistencia de la mortal herida de Cupido, le hizo olvidar la nueva compañía, rindiéndose a la ausente señora, sin considerar que era hermana de la que consigo tenía por muger. Pues acrescentándosele cada un día el nuevo amor, fatigándole con nuevo desseo, consideraua como podía auer remedio de la poder gozar, sin que nadie fuesse parte para se lo impedir. Finalmente puso por remedio cauteloso, embiándomela a pedir, para que su hermana Melinda pudiesse passar con algún tanto de gusto, un enfadoso preñado que tenía: y que dezía que passaríalo con mucho más alivio, teniendo en su compañía a su hermana, que más que a sí la quería. No aduertido del mal que me pudiera en 
la embiar suceder, púsele escusa, que a causa de mi recreada vejez que con ella passaua, no me atreuía a se la embiar, entendiendo que se dolería de verme quedar solo: lo que el Rey sintió mucho. Pero con astucia lo dissimuló, hasta que fue parida mi hija y muger suya Melinda, y entendiendo, que con el gozo del nueuo infante no me escusaría, otra vez boluió a me embiar por ella. Yo siempre firme de no la dexar ausentar de mi presencia, como regalo de mi alma. Visto por el traydor, él mismo, en persona, con poderosa armada, vino a se la lleuar. Yo que supe su venida, con gran pompa le salí a recebir, y con amoroso rostro me rogó, le mandasse dar mi hija, para contento de su muger, que más que a sí la amaua. Tuuieron tanta fuerça sus cautelosas razones, que yo no pude escusar, de lo que con tan blandas y amorosas palabras me pidió. O inmorales dioses, que tan encubierto hizistes el coraçón del hombre, que solos vosotros soys capaces de saber el bien, o mal que en él se encierra ¿quién pensara, ni creyera, que el traydor Rey, con tal dulces razonamientos, y cautelosos contentos, uno solo que yo tenía me robara? Luego que vuo alcançado lo que de entrañas desseaua, no aguardó un punto su partida, dándome a entender procuraua sin más dilaciones, lleuar lo que tanto contengo a su muger auía de causar. Mi coraçón sentido, no de lo que auía de suceder, pues no lo alcançó a saber, pero de ver partir la que mi coraçón lastimado con su ausencia dexaua, daua muestra en los ojos, con lágrimas que a ellos embiaua la passión que esperaua. Tanto, que sin sentido me vuieron de boluer al palacio. Casi no se vuo embargado, celoso de que no fuesse entendida su trayción, mandó dar velas al viento. Fortuna, que le ayudó con próspero tiempo, fue a arribar a su tierra con gran brevedad, a dos leguas de la ciudad, y con gran magestad fue recebido de los suyos, trayéndole cauallos, y palafrenes. Puestos que fueron en orden tomaron su camino. Sujeto el falso Rey a su mal propósito, mandó, que toda la gente se fuesse adelante, quedándose él solo algo alexado de los suyos, con sola mi triste Herea. Y quando se vio solo con ella, guiándola a una parte de un bosque que allí estaua orilla de un río por do caminauan, la metió en lo más encubierto (que bien aduirtido dello deuía de estar) y apeándose de su cauallo, dixo a mi querida y regalada hija, que assí mismo se apesasse. Ella, que no auía reynado en su coraçón algún género de sospecha, se apeó: assentándose orilla del corriente río, y lauó sus blancas y hermosas manos, refrescándose la boca en él. El fingido regalador, no dexaua con algunas muestras y encubiertas palabras, dar a entender el encendido fuego de amor que le atormentaua, declarándole su dañada intención. Fatigada ya de las continas razones mi amada hija Herea, como leona furiosa le reprehendió, diziéndole lo que a tal caso requería. Lo que visto del insano Rey, quan aceleradamente le respondía, queriéndosele leuantar del assiento do estaua, la asió de la ropa y la detuuo, y con palabras blandas la quiso boluer a sossegar, diziéndole:

- O infanta mía; por qué quieres que muera a causa tuya, pudiéndome remediar sin ser sentida? No seas auara en concederme lo que, con tan sobrado amor te suplico, quién ay aquí que pueda ser testigo de mi atrevido desseo, ni de tu demasiada largueza? no otro por cierto, sino los dioses immortales.

Ten por cierto señor, que Iúpiter más dolor tenía de mi mal, que no de tu pena.

La engañanda infanta que se vio asida de la traydora mano, con rauia furiosa le dixo:

-No pienses traydor que tienen poder tus maliciosas palabras, a mouer mi coraçón a conceder con tu luciferino pensamiento: yo te juro por los soberanos dioses, que antes 
permitiré que mi cuerpo sea hecho pieças, que dar oydos a tan grande trayción; déxame Rey, mira que soy hermana de tu muger, que acaso con la furia, y demasiada embriaguez que tienes se te aurá oluidado: determina de me dexar, si te pluguiere, o cree que tengo de morir en mi desfensa.

Viendo el maluado Rey, que la casta infanta se le defendía, ásela del pescueço, diziendo:

- No pienses, o cruel Herea, que te has de librar de mis manos, sin conceder a mi voluntad y desseo, que te prometo, en pago de la crueldad que comiga usas, aurás la más cruel muerte, que jamás donzella passó.

La triste señora no le espantaua nada el auer de morir, y sin temor alguno respondió:

- No pienses traydor, falso, que el temor de la muerte me tiene de rendir a tu desseo.

Lo qual viendo el Rey dixo:

- Sábete infanta, que viua, o muerta he de cumplir mi desseo, que con tanto fuego me abrasa mi coraçón.

Tan fuertemente se defendió, que con varonil ánimo guardó su honra.

No pudiendo su mal desseo seer cumplido, con gran rauia, que el encolerizado Rey tenía, le cortó gran parte de la falda del vestido, y asiéndola fuertemente de los cabellos, la maltraxo, tanto, que con la sangre que de la cabeça le salía, matizaua la verde yerua.

Con esto creyó, que algún tanto la assossegaría. Viéndole tan mal tratar, mientras más lo procuraua, mayor furia la infanta la mostraua. Visto por el traydor, que no le aprovechaua, va perdiendo la fe de cauallería, y el respeto que a quien era deuía tener, blasphemando contra el cielo, rasgándole a pedaços sus ropas, la desnudó, y con las riendas del palafrén crueles açotes le daua en sus delicadas espaldas, matizándolas con azules señales, y todo le aprouechava poco. Viendo la perseuerancia que la infanta mostraua, añadiendo crueldad a crueldad, sus blancas y bien compuestas piernas, con sus rollizos braços con unos cordeles agarroteó, y la ató a un árbol muy fuertemente diziendo:

Cruel más que muger en el mundo ha sido; Por qué has querido venir a estar desta manera, a trueco de no dar gusto a quien perpetuamente le diera? Parécete que es mejor padecer semejante martyrio, que no una gustosa y amorosa vida? La maltratada infanta le respondió con voz ronca:

- O cruel traydor más que ningún cauallero lo ha sido: Por qué te reparas di, vil enemigo de los dioses, que no acabas de sacar esta alma deste mísero cuerpo? Házeslo por que no se vaya a quexar a donde te sea dado el castigo de tu aceruíssima crueza? O dioses, no me neguéys la justicia contra este falso y traydor rey, no perdays el nombre de justicieros por amparar tan maldito rey.

Con esto cansada del terrible dolor y tormento que passaua calló.

No por esso el Rey dexó de proseguir su crueldad, antes con gran rauia la miraua, teniendo los ojos libidinos enclauados en ella. Viéndolo la atormentada señora, codiciosa de la muerte, con voz furiosa le dixo:

—Qué piensas traydor, el mayor de los traidores? Qué contemplas carnicero, desapiadado tigre, luxurioso puerco, deshonrador de la real corona? Acaba ya de atormentarme, que ya no es tiempo de te arrepentir. Dame la muerte, embiándome a par del seno de Diana. 
Viendo el desapiadado Rey la perseuerancia que tenía en la defensa de su honra, con ánimo cruel, toma vna toballa que la infanta al cuerpo ceñida tenía, y, con brutal yra se la echa al cuello, apretándola hasta que del cuerpo se despidió el ánima.

O caballero, que a ver y poder leer esto alcançares, considera la castidad y constancia de la sinventura, muéuate a dolor muerte tan cruel, para que con mayor voluntad procures su vengança.

Viéndola el endemoniado Rey muerta, boluió a seguir su camino: a poco rato alcançó a los suyos, lleuando el semblante tan feroz y ayrado, que ninguno se atrevió a preguntar por mi hija.

Vno de los caualleros de mi corte, que a acompañarla yua, tomando alguna sospecha de la alteración que el rey traýa, deseoso de saber qué le auía hecho la infanta, que sola quedaba, sin que pudiessen echarlo de ver, se quedó algo atrás, y siguiendo las pisadas que el cauallo auía traído, hasta llegar do auía sido la folla de la dolorosa muerte, viéndola de la suerte que se te ha contado, quedó tan sin sentido, que casi muerto se cayó en tierra.

Buen rato estuo el cauallero sin poder hablar. Buelto que fue en sí, con un doloroso llanto, clamando contra los dioses y fortuna, que tanta crueldad auían consentido, y desatándola del árbol, la puso sobre sus ropas, y cubriéndola así mismo con ellas dezía,

-O manos crueles, quál coraçón cruel os pudo acompañar, a hazer semejante sacrificio? Mouiéraos a piedad belleza tan grande.

Con semejantes lástimas hablaua el cauallero con el difunto cuerpo, y desgajando dos ramas de los árboles para poder mejor cubrir el cuerpo, de tal manera le dexó, que no parecía, sino ser montaña de arboledas hecha. Esforçándose lo mejor que pudo, dissimuló el saber semejante caso: y como mejor pudo caualgó en su cauallo, boluiéndose hazia la ciudad y corte del Rey. Tan apriessa caminó, que los vuo de alcançar a la puerta de la ciudad.

El Rey se apeó, y sin querer ver a nadie, se encerró en su aposento.

El cauallero de mi corte tuuo tiempo de contar a la Reyna lo que auía visto, y el amargoso fin de la infanta Herea su hermana. Tanto fue el sobresalto que la reyna vuo acompañado de yra, que mandó al cauallero no se fuesse de la Corte, hasta auer más ocasión.

La reyna se quedó haciendo grandes lamentaciones entre sí, por no ser sentida, y con voz baxa dezía.

- O reyna sin ventura, nascida en triste hado, que veniste a estar sujeta al más cruel rey de los reyes, no podrá tanto la fortuna serme contraria, que no pueda tomar vengança de ti. O inmortales dioses, vengadme de tan acerua muerte, sino yo os juro de hazer de mi mano tal obra, que vosotros de lo ver desde los cielos os atemorizéys. Qué hazeys sordos y sin justicia, no quereys oyr mi llanto triste? Pues yo veré si soys poderosos a me escusar de no hazer mi voluntad.

Toma en su mano vna daga, que del Rey era, y en los braços su pequeñito hijo le yua diciendo. No haré yo tanto mal al mundo, que dexe hijo de tan mal padre en él. Fuesse al aposento del Rey y hallolo tendido sobre la cama, rebolcándose a una parte y otra, sin poder un punto reposar, y llorando a grandes vozes, llamándole de tryador, con la daga que lleuaua le atrauessó la garganta al inocente niño, y como leona se lo arrojó sobre el lecho, diziendo:

- Toma, traydor, el fruto que hiziste en mi vientre, y arrójase tras él para lo matar, 
quiso su ventura, que no le acertó en lleno. El Rey que de ver lo que la Reyna auía hecho algo turbado estaua, ásela de los cabellos, maltratándola muy mal. Ella viendo que auía errado el golpe, y que ya no podía poner en effeto lo que auía pensado, buelue contra sí misma la rauiosa, furiosa y la ensangrentada daga se mete por el coraçón, que dos partes se le hizo, quedando muerta en manos del causador de tantos daños. Fue tanto lo que el falso Rey sintió, que no supo que consejo tomar, y adeuinando el castigo que le podía del mal sucesso, con gran secreto hizo que el cuerpo de la Reyna se enterrasse, y fue auisado por vn sabio de su corte, que por la maldad que auía hecho se auía de destruyr su reyno, y venir a manos de la cosa que él más desamaua, que es un sobrino suyo.

El Rey auisado de lo que podía suceder, usó de un ardid; y fue, de poner guardas en su reyno y prender quantos en el desembarcassen, y no dexarlos hasta que con firme juramento les prendaua las palabras, que en defensa suya serían, hasta perder las vidas, dándoles a entender, que sin culpa, se la querían quitar.

El cauallero que auía visto todo lo passado, vínose como mejor pudo a mi corte, y me dio las tristes y amargas nueuas para mi.

Buen cauallero, considerad lo que este sinventura Rey sentiría? Atajómelo vn gran sabio llamado Artemidoro, que a consolarme vino, asegurándome que sería vengado de vna muy poderosa mano, aunque primero auría muy poderosas batallas, y que creyesse que me dezía verdad.

Como el sabio es tan conoscido, dí crédito a sus palabras, suplicándole de su parte hiziesse lo que a mi vengança convenía. Luego lo puso por la obra, y hizo decender vn carro, y me puso en él, y donde mi hija estaua me lleuó en vn punto, mandándome la pusiesse en el carro, y la truxesse a esta isla, asegurándome, que el que venciesse las guardas que allí dexava, sería el vengador de mi injuria.

Y pues ya has vencidos los guardadores, que el cuerpo de la infanta a cargo tenían, cumple el juramento que tienes hecho como cauallero. Y para lo cumplir hasta de yr a Cimarra a donde yo el desuenturado Rey te estaré aguardando.

Muchas lágrimas derramaron el Emperador y su compañía con la triste historia, acrecentando el desseo al Emperador de la vengança. Y con semejante desseo se boluieron a la mar, y auiéndose ya sossegado boluieron a su començado camino.

\section{I}

Fray Juan de PIneda, Diálogos familiares de la Agricultura Christiana, 1589. Diálogo IV, capítulo IV-V BAE, vol. 161, págs. 242-244.

\section{[FÁBUla DE] FiLOMELA}

POLICRONIO: Con romanzar la letra de Ovidio satisfaré mi obligación diciendo que a mil trescientos y ochenta años primero que nuestro Redentor nasciese en carne humana, vivía el rey Pandión, primero deste nombre y quinto entre los reyes de Atenas; el cual tenía dos hijas llamadas Filomela y Progne, y a la mayor, Progne, casó con Tereo, rey de Tracia, que le parió un hijo llamado Itis. 
$\mathrm{Al}$ año quinto de su casamiento rogó Progne a su marido Tereo que diese orden en cómo ella pudiese verse con su hermana Filomela, o llevándola a ella a Atenas o trayendo de Atenas a Filomela a Tracia; y con esto fue Tereo a Atenas, y tanto hizo con el suegro, ayudado de las lágrimas de Filomela, que el suegro se la dio sobre su palabra real que se la tornaría sana y honrada, cual se la entrega.

Con la compañía de la doncella, hermosísima y generosa, se encendió el barbarazo Tereo en su amor, y, disimulando en cuanto fueron por la mar, en saliendo en su tierra, la llevó a un monte y la forzó; y por verse baldonar della por traidor y amenazar que le había de pregonar por el mundo, la cortó la lengua, y aun después la tornó a forzar, cosa que parece increíble. Allí se la dejó en unas caserías en guarda de unos pastores y llegado a su mujer, la hizo entender con lágrimas que se le había muerto; con lo cual Progne se cubrió de luto y se derretía en llanto.

Un año estuvo allí Filomela detenida; y habiéndola hecho aguda la rabia de la venganza, buscó hilado, con que en un bastidor labró una pequeña tela de blanco estambre, tramado de letras coloradas, en que brevemente dio a entender lo que pasaba de sí, y por señas alcanzó de una mujer que la llevase muy corriendo a la reina. La reina Progne se tornó una leona contra su traidor marido, habiendo entendido las letras de la telilla, y pensó mucho cómo se podría vengar dél y recoger a su hermana; Y, habiendo llegado el día de las fiestas del dios Baco, en que las mujeres tracianas salían por los campos y montes coronadas de pámpanos y vestidos, conforme al misterio, haciendo visajes como espiritadas, ella salió fingiéndose muy arrebatada del báquico furor, y caminando al monte, donde la informó la mujer, que su hermana estaba, la vistió como a báquica y se tornaron las dos a casa sin ser entendidas de ninguno.

Las dos se dieron a trazar cómo se vengarían del traidor Tereo, y, estando en ello, entró el niño Itis, hijo de Progne y de Tereo, y concluyeron que con aquél se vengarían de su padre; y luego le mataron, y hecho pedazos, le cocieron y asaron; y fingiendo Progne cierta fiesta y religión al uso de su tierra, convidó a comer a solo Tereo, su marido, en su aposento; y allí le dio a comer las carnes de su hijo, de que se hartó; y, como preguntase por su hijo y diese priesa por que se le llevasen a su presencia, Progne le dijo que lo que pedía en el estómago lo tenía; y luego salió Filomela con la cabeza del niño y le dio con ella en la cara, bien apesarada por no le poder decir tales injurias cual se las hacía.

Él, que vio lo que pasaba, dio con la mesa en tierra y arrancando de su espada, echó tras ellas por vengar su injuria y la muerte de su hijo; y ellas echaron a huir. Y Progne, ya que la iba en alcance, fue convertida en golondrina, y le quedaron algunas gotas de sangre en el cuello, de las que la salpicaron cuando degolló a su hijo Itis, y por más que huyó la trabó Tereo de la falda y le quedó un pedazo en la mano, como agora lo muestra la golondrina en el medio de su cola, que la tiene gastada de allí; y como se había criado en grandes palacios, como reina gran señora, se quedó en poblado, y siempre procura morar en casas grandes, y su canto apresurado muestra la turbación con que quedó de aquellas turbaciones tan escandalosas.

Filomela fue convertida en el ruiseñor, y afrentada de su corrompimiento tan ignominioso, siendo ella tan real doncella, se fue a morar a los bosques con su lengua despicada, como agora se ve en ella; y aunque su canto es dulce y armónico, es lastimoso, y sus silbos parecen exclamaciones que piden venganza. 
El rey Tereo fue convertido en abubillo, y siempre le quedó la insignia de la corona real en la cabeza, y con el canto le duran las amenazas, que derrama con mala y confusa pronunciación pidiendo $p u-p u$, que quiere decir adónde, adónde, como si preguntase por ellas para las ir a matar adonde estuviesen.

El niño inocente Itis fue tornado en faisán, ave de gustosísimo sabor, bien como manjar real, y por eso hay pocos; y como fue guisado de diversas maneras, ansí, tiene agora diversos sabores.

Higinio dice de Tereo que, como tuviese oráculo de sus dioses que su hijo Itis había de morir a manos de una persona muy conjunta, que él sospechó ser su hermano Driante, que por haber el reino le quería matar, y por eso le hizo matar sin razón, y que él fue convertido en halcón, ave cruel y de rapiña, cual hombre había sido.

PÁNFILO: Graciosa es la narración poética, y bien ha mostrado el señor Policronio que trae bien ejercitada su memoria; mas si tenemos por Sant Pablo que aun la letra de la Escritura sin spíritu es sin provecho, mucho más lo es cualquiera escritura humana, y mucho más la poesía; por tanto, señor Maestro, bien será decirnos algo que valga.

FILALETES: Alguna controversia se halla sobre cuál de las hermanas es la que se llama luscinia o ruiseñor; y luscinia, palabra latina, quiere decir ave cantadora, cuando asoma la luz del día, como Filomela en griego; porque Papinio, Marco Varrón, Plutarco, Aristóteles, Sófocles, Probo y aun Virgilio parecen decir que Progne se convirtió en ruiseñor, y Aristófanes tiene lo mesmo y Anacreonte, a quien se atiene Alciato, sino que parece que confunde a la una con la otra; y otros, sin los dichos, tratan de soltar este ñudo, y en caso que sea tan importante como el del yugo de Gordio, con un tanto monta del grande Alejandro le podremos cortar y cumplir con él; y concluiremos con decir que lo común tiene que Filomela es el ruiseñor y Progne la golondrina.

Y Pedro Nanio da una concordancia bien llena de confusión a esta duda; diciendo que los poetas no tienen por inconveniente confundir las cosas cercanas unas con otras, y que, como los cuentos de Filomela y los de Progne anden revueltos, dan a la una lo que se debe a la otra. Esta razón es mal aplicada, porque en caso que la semejanza de los nombres o de los hechos dé licencia para que los poetas apliquen a uno lo que es de otro, aquí no hay semejanza en los nombres ni en los hechos destas dos hermanas; si no que la una anda diferenciada en todas sus cosas de la otra.

Pausanias en su primer libro dice que muchos de sus vasallos se rebelaron contra el rey Tereo, por sus maldades, y que no los pudiendo reducir en la ciudad Daulida, y después se mató en la ciudad de Megara, donde fue sepultado, y cada año bien ofrendado; y que allí fue visto primeramente el abubillo con su cresta real, y que por eso dijeron que Tereo se había convertido en él, recompensándole su suciedad carnal con la de este pájaro, del cual dice Aristóteles que fornece su nido con estiércol humano, y aun Plinio dice que se mantiene con suciedad.

Las dos hermanas dice Pausanias que huyeron para Atenas, su tierra, y que, derretidas en lágrimas por lo que padecieron de Tereo y cometieron contra el niño Itis, murieron, y que, por tanto, le parece haberse compuesto aquella fábula dellas, porque ambas avecicas cantan llorando. 
También digo que por carecer el ruiseñor del piquillo de la lengua (lo cual afirman Plinio y Aristóteles) como se dice haber carecido la señora Filomela, y, porque la golondrina tiene una gran muesca en medio de las plumas de la cola, como se dice haber Tereo arrancado parte de la falda de Progne, fingieron haberse convertido aquellas mujeres en estas aves.

\section{[EL] RUISEÑOR Y [LA] PiCAZA}

PÁNFILO: De la manera que contó el señor Policronio con Ovidio el haber dejado Tereo a Filomela en el monte, se aparta Higinio diciendo que la envió al rey Linceo debajo de confianza de amigo y que ahogó en el mar a cuantos con ella partieron de Atenas; y que Letusa, mujer del rey Linceo, la envió secretamente a su hermana Progne, y esto va más historial.

FiLALETES: Esto son cuentos de niños de escuela o patrañas de vieja, y que en la niñez se aprenden y en la vejez se deben reducir a buena doctrina, so pena de se perder el tiempo que en ellos se gasta.

FiLótimo: Animaos, señores, que ya entramos por los regadíos donde refrescaréis los pulsos con aguas frías, y los oídos con la música de la señora Filomela; y veis las vislumbres que hacen los plateados capiteles de la torre grande de la granja, heridos de los rayos del sol, y especialmente que todas sus chimeneas humean, que en tiempo de calores no será sino por guisar de comer; y me parece que es probación de abastada comida.

Atended por mi vida al ruido que hace y obra que mete con el arpar de su voz, la nuestra Filomela en aquella mata de madreselva, que no siendo mayor que un gorrión, tiene voz para henchir un gran cuerpo; y represéntaseme lo que ya dijo de la perdiz, que por haber sido despeñada de alto, volaba y nidificaba en bajo, y que ansí el ruiseñor se anda por los zarzales y matorrales haciendo en ellos su nido, no queriendo probar alturas, escarmentado en sus mujeriles desventuras.

La golondrina no ha querido descaer de su pundonor real, y se anda siempre entre la gente y busca los sotambanos y techos altos y descombrados donde hacer sus nidos; y puesta en un palillo gorjea tanto que atruena la casa, replicando siempre aquella sarta de maldiciones que descargó sobre Tereo, cuando fue convertida en ave, y, porque no puede perder queja de mal casada, nunca dice otra razón, y siempre la lleva medio atropellada, rematándola con sonido rencilloso.

POLICRONIO: Descomedidos y desagradecidos nos mostramos con la señora Filomela, que recibiéndonos ella con su música, nosotros no la prestamos atención; y no fuera mucho que a ser de las aves parladeras, nos hobiera saludado en arábigo, pues habla mucho de garganta, y no conversa por aquí sino con moriscos que labran estas huertas. Por tener anchas lenguas dice Ateneo que parlan algunas aves.

PÁNFILO: Papinio bien concede que los ruiseñores deprenden a hablar, y aun Plinio afirma que Druso y Británico, hijos del espurcísimo emperador Claudio, tovieron ruiseñores que hablaron, ansí en la lengua griega, como en la latina.

FILÓTIMO: No llegué yo a tanto griego con ser hombre, haciendo punto en los contractos, y maravilla parece tal hablar; mas a lo menos de la dulce música que hacen, 
dicen Aristóteles, Plinio y Plutarco maravillas, sin que os pongáis a censurar cuál sea más la variedad de la voz del pájaro o la elocuencia y abundancia de palabras con que Plinio nos lo significa.

Dende que el pintor del mundo comienza a revestir los árboles de hojas verdes, comienza su canto nuestro pajarito, y por quince días parece haberse derretido en voces, sin jamás callar; y con tantas diferencias gobierna su armonía, que quien eso no lo supiere ni le viere, juzgará ser muchos pájaros los que tal música componen: ya de recio, ya de quedo; ya de espacio, ya de apriesa; ya de acerca, ya de lejos; ya con puntos enteros, ya con semitonados; ya silba, ya gorjea; ya arpa, ya reclama, de arte que oyendo a uno podéis hacer cuenta que oís a una capilla de cantores.

Por haberse sentado uno en la boca del poeta Estesícoro, siendo niño chiquito, y cantado allí, se tuvo por prognóstico de que había de ser de admirable elocuencia poética, según lo fue el sueño del cisne que Sócrates tuvo de la elocuencia filosófica de Platón.

Contienden unos con otros en desafío aplazado y acontece morir alguno primero que deje el campo, en tanto estima la gloria de su cantar; para lo cual estudian y tienen sus ratos de meditación y imaginando nuevas diferencias de consonancias que enseñan los padres a los hijos, y les hacen cantar, tornando a los corregir de lo mal cantado, con cierta manera de reprehensión y castigo.

También se han visto cantar a versos con los instrumentos humanos, mandados cantar o callar, según que semejantemente yo he visto, como lo dice Plinio a hombres imitar el canto destas avecitas, teniendo una delgada porreta en la boca.

Como entran las grandes calores, se les muda la voz, y pierden las muchas diferencias que antes hacían, y truecan el color de sus plumas; y prueba Plutarco que no les es todo su canto natural, sino en parte enseñado por el magisterio paternal y deprendido por su estudio y diligencia; con que los que dellos son enjaulados, dende pequeñitos, no hacen tan vario y armónico canto como los que se han criado con sus padres.

POLICRONIO: Cosas son éstas que muchos las ternán por composturas.

FILALETES: El cuento de una picaza que por información de muchos testigos de vista pone Plutarco, hace fácil de creer todo lo dicho: que un barbero tenía en Roma su casa en la plaza llamada de los griegos, y crió una picaza, tan parlona del lenguaje humano y tan remedadora de muchas de las voces de los otros animales, hasta bramar como buey, que por ello era muy afamada en Roma. Aconteció que cabe la casa del barbero murió un hombre rico, cuyo enterramiento fue muy solenizado con larga música de diversos linajes de trompetas, conforme al estilo antiguo; tocado en el Evangelio; y la picaza quedó tan muda que ni aun su natural cherriar y gorjear ejercitaba, y por muchos días se creyó estar hechizada. Ya estaban descuidados de su hablar, cuando repentinamente salió un día con su ruido de trompetas tan bien imitado y contrahecho y con tantas diferencias, cuantas pudo haber oído a los tañedores. Con lo cual se persuadieron todos que había estado estudiando la nueva disciplina de las trompetas por el tiempo que guardó silencio, y ganó más palmas por trompetera que había ganado por parlera.

POLICRONIO: ¡Bendito sea Dios, que un pájaro por oír una vez una música la deprendiese, poniendo estudio para ello, y que tenga yo un sobrino en la iglesia con bue- 
na renta de beneficios, y que, habiendo más de quince años que le ordenaron de misa, no la sabe agora.

\section{V}

PERo SÁNCHEZ, Triángulo de las virtudes teologales: Fe, Esperanza, Caridad, y cuadrángulo de las cuatro virtudes cardinales: Prudencia, Templanza, Justicia, Fortaleza, Toledo, 1591.

ARTículo 20. De vna historia lastimosa, y muerte de vna Infanta que sucedió de la fuerça de amor

Dizen las historias antiguas, que ovo vn Rey en el reino de Cimarra el qual tenía dos hijas, las más hermosas que naturaleza formar pudo. De las mayor de las quales, llamada Melinda, sin la auer visto, fue preso de amor Norlaldino, rey de Numidia, Rey tan poderoso como falso, y cruel. El qual con grande instancia la embió a pedir por sus embaxadores al Rey su padre para que se la diesse por muger. El qual holgó de aceptar el casamiento, y se la embió, con la pompa y aparato que a tal princesa conuenía. Y (celebrado el matrimonio) tales nueuas le dieron los que la auían traído, y de tal manera le exageraron la hermosura de la otra hermana (que Hera se llamaua) los embaxadores que auían traído a su esposa, que sin aver en él alguna resistencia, ni tener respecto a que era hermana de su muger, se rindió al amor deshonesto de la cuñada, y vino en gran aborrecimiento de la hermana que era su propria muger (tanta es la fuerça de el amor libidinoso) y no entendía en otra cosa sino en imaginar medios y traças en su entendimiento, como pudiesse satisfacer a sus desordenados desseos.

Y con engañosa cautela, acordó de embiársela a pedir al padre, fingiendo que sería gran gusto y contento para su muger verla, porque estaua muy enfadada de vn molesto preñado, y que sentiría gran aliuio con la presencia de su hermana. Escusó su demanda el viejo padre, diziendo que era el consuelo y báculo de su vejez aquella hija, y todo su regalo, y que no podía vivir si salía de su presencia su querida infanta. Mas esta negación fue echar azeite en la fragua de amor que ardía en el libidinoso coraçón, y ansí tuuo nueuas ansias, y tormentos que le causauan las flechas que le tiraua el cruel $\mathrm{Cu}$ pido, y como se llegasse la sazón del parto de su muger, Melinda, embió otros embaxadores, suplicando al suegro, que se la embiasse, para regalar a la parida, y quedarse con ella, porque no quedasse sola, que él auía de hazer cierta ausencia. Mas con todos estos ensayos, no pudo mouer el ánimo del buen Rey, que parece que adevinaua el mal sucesso, y ansí se la negó segunda vez. Visto esto por el traydor yerno, eran tan biuas las ansias que tenía del amor de la infanta, que él mismo se determinó de yr por ella. Y llegado a la presencia del suegro, se la pidió con fingidas razones y se la suplicó con grande instancia se la diesse, para regalo de su muger, que estaua muy melancólica, y en continuo desseo de ver a su hermana. Tuuieron tanta fuerça sus cautelosas palabras, que como la gotera que cayendo muchas vezes, y con gran furia, sobre la piedra (por dura que sea) le haze mella. Ansí hizieron mella sus persuasiones, en el coraçón del buen viejo, que tantas vezes auía negado su demanda, y le concedió lo que pedía, fiándole (que no deuiera) su hija, que era la lumbre de sus ojos. Y él (encubriendo el diabólico intento que el diablo le auía puesto en el coraçón) sin dilación ninguna, tan an- 
sioso estaua de poner en efecto su dañada intención, adereçó su partida, y metiéndose con ella en vn nauío, dio velas al viento, quedando muy desconsolado el pobre Rey, su suegro, aunque bien sin sospecha de lo que el traydor yerno tenía en el coraçón (cuyos secretos sólo Dios escudriña, y alcança) y muy lastimado derramaua muchas lágrimas por la partida de su amada hija, y mucho más de veras llorara, si entendiera lo que el traydor yerno lleuaua ordenado en su coraçón.

Ayudado el libidinoso Rey, de próspero viento, llegó muy en breue a vista de su reyno, donde le salieron sus vasallos a recebir con gran pompa y autoridad, y le traxeron cauallos, y palafrenes, y las demás cosas necesarias para su entrada. Mas (no sufriendo su dañado pensamiento más tardança) mandó que todos se fuesen adelante, y él se quedó con su cuñada Hera, en vna ribera, en vn lugar escondido, debaxo de vnos olmos, y hermosa arboleda, donde le dixo, que era bien apearse, y descansar del trabajo de la nauegación, en tan deleytoso lugar. Y como ella estuuiesse sin ninguna sospecha de su dañado propósito, se apeó, y se assentó sobre la fresa yerua, y en la corriente de aquel apazible río, se refrescó, lauándose el hermoso rostro, del polvo del camino, y sus hermosas, y blancas manos, donde el falso Rey le hizo muchas caricias y regalos, y le dixo palabras blandas, y amorosas. Las quales ella echaua a buena parte, hasta que le començó a llegar al rostro, y a dar otras muestras manifestadoras de su desordenado amor.

Cayendo, pues ella en la cuenta, se alexó algo dél, y indignada de su atreuimiento, le reprehendía su locura, y alegaua el parentesco, y la confiança con que en su poder se la auía entregado el Rey, su padre. Mas él, no persuadido con sus razones, dando lugar a la passión, la asió de las ropas, juntándose con ella, y pensó que con palabras blandas la haría rendir, y comiença a limpiarle las lágrimas, que a hilos corrían de sus ojos, por verse en tal aprieto, donde no auía quien la pudiesse socorrer, como otra Susana, quando estando encerrada, en aquel huerto, la quisieron forçar aquellos malos viejos. Y díxole:

-O hermosísima señora ¿por qué quieres que yo muera a causa tuya, pudiéndome remediar, sin que nadie sea testigo, sino los dioses inmortales? los quales no lo tendrán a mal, antes se dolerán de mis pasiones pues ellos han pasado por casos semejantes, y no tienen por yerros los que proceden de amor: ni estamos en parte donde ninguno pueda ser testigo de tu liberalidad, otorgándome lo que con sobra de amor te demando.

No pienses, respondió la honestíssima infanta, que han de tener poder tus maliciosas palabras, a mouer mi coraçón a condecender con tu luciferino desseo, antes te juro por los inmortales dioses que trabajas en vano, porque antes consentiré que mi cuerpo sea hecho mil pieças que condecender con tu dañada trayción (Mira Rey peruerso) que soy hermana de tu muger, que por ventura con la demasiada embriaguez que tienes se te aurá olvidado, determina de mudar propósito, o ten por cierto, que tengo de morir en mi defensa. A lo qual replicó el cruel cuñado:

-No pienses, cruel Hera, que te has de escapar de mis manos, sin condeceder con mi desseo, antes te juro que te daré la más cruel muerte que jamás se dio a mujer, por la crueldad que conmigo vsas.

A esto respondió con ánimo varonil, la castíssima Infanta:

- No pienses traydor falso, que tus amenazas, ni el temor de la muerte, me han de hazer rendir a tu desseo.

Luego con la gran rauia, que el encendido Rey tenía, la asió tan fuertemente de los cabellos, que dio con ella en tierra, y con la sangre que le salía del rostro se matizaua la verde yerua de aquel campo. Y pensando que con esto la haría amaynar, tornó a porfiar 
en su demanda, y a procurar de alcançar por fuerça lo que de grado no podía. Mas, ni por essas, ni por essotras, no pudo salir con su intención. Y viendo el maluado Rey, que no la podía mellar por ruegos, ni amenazas, ni castigo, la desnudó a pedaços de todas sus ropas, y la dexó en cueros, y con las riendas del palafrén, atándola a vn árbol, le dio muy crueles açotes, mezclando, entre vno, y otro, algunos ruegos, y amenazas. Mas mientras el usaua de mayor crueza, ella mostraua mayor constancia. Y él tomó ramas, y cortó varetas de los árboles, con que teniéndola bien agarroteada en el árbol, le hizo grandes cardenales y heridas en los delicados braços, y piernas, y otros miembros, lastimando, y hiriendo como vn cruel sayón, aquellas delicadas, y hermosas carnes.

Llamaua la lastimosa donzella, el fauor de los dioses, y de los hombres, y pedía vengança del facinoroso Rey.

Estaua el lobo carnicero, mirando el lastimoso expectáculo, muy bastante para ablandar vn coraçón que fuera de diamante, y a qualquier tigre, y bestia fiera. Mas él, más feroz y rauioso se mostraua, como el perro rauioso, que no se harta de dar bocados al animal que tiene entre sus rauiosas vñas, y manos. Estaua muy pensatiuo, imaginando, qué género de muerte le daría, con que satisfiziesse a su enojo. Y viéndole ella ansí suspenso, le començó a dezir:

-Qué piensas traydor, el mayor de todos los traydores? Qué contemplas desapiadado tigre? Qué imaginas suzio, y luxurioso puerco? Deshonra de la real corona, infamia de Reyes, afrenta de caualleros, que tienen jurado de no consentir, quanto más, hazer fuerça e injuria a ninguna muger. Qué rumias entre ti, oprobio, y afrenta de los hombres? Piensas darme nueuos tormentos, para alcançar de mi lo que desseas? Pues aunque me hagas pieças, no te verás en esse gozo. Por ventura estás pensando, si será bien halagarme, y quitarme del tormento, y tomarme la sangre, entendiendo que satisfaré a tu desseo, por temor de más tormentos? Pues engañado estás, que si mil vidas tuuiera, todas las perdiera por defender mi honestidad.

Viendo pues este Rey tirano, y deshonestíssimo, que no podía por mal efectuar su mal desseo, y quiso intentar, si podría por bien, y quítala del tormento, y halágala, y límpiale la sangre de las heridas que le auía hecho, y enxúgale las lágrimas. Mas como todo esso no bastasse contra el castíssimo pecho de la Infanta, procuró de alcançar por fuerça lo que no podía de voluntad. Mas tampoco aprouechó este medio como los demás. Porque ella defendió su honestidad valerosísimamente. Y ansí, haziendo (como ella hizo) lo possible qualquiera donzella (aunque fuesse forçada por más no poder) no perdería el tesoro de su virginidad, aunque padeciendo fuerça, la perdiesse contra su voluntad, antes grangearía desta fuerça (siendo christiana, y teniendo respecto a Dios) laureola, y gran caudal de merecimiento, como lo dixo la bienauenturada Sancta Lucía, y lo tenemos en su leyenda, que la amenazaua el tirano, de que la haría poner en el lugar público, para que allí fuesse afrentosamente violada. Si por fuerça, y contra mi voluntad fuere forçada (dezía ella) doblárseme ha la corona de mi castidad. Lo qual se contiene en el Derecho. Verdad es, que a la que esta fuerça le acaeciesse, ipsa corrupta maneyte, no se podría consagrar entre las virgines, como dize el capítulo IIIc: más no porque aya perdido la integridad con la fuerça, perdió la virtud de la virginidad, ni el premio della. Mas la que, saluo claustro virginitatis, reciperet semen virile, no se podría tener por doncella, porque en este caso (que es muy possible) podría concebir, como dize Pedro de Palude, y lo allega el Florentino, en la tercera parte, y quando viniesse a parir perdería la integridad. Y es cosa notable, que podría uno ser concebido 
(como lo nota el mismo autor) de padre, y madre vírgines sin corrupción per semen emissum a patre dormiente, daemone sucubu recipiente, possea per eundem demonem, factum incubum trasfusum in feminam virginem, salvo claustro virginitatis. $\mathrm{Y}$ en tal caso ella podría concebir sin corrupción. Y si alguno la pareciere impossible este caso, yo le remito al lugar citado. Y allá se lo ayan con el Florentino.

Mas tornando a la fuerça que quería hazer el deshonestíssimo Rey a nuestra Infanta, teníala entre sus braços como tiene el gavilán al páxaro, y el açor a la perdiz entre sus crueles uñas. Mas por más picadas que le daua, nunca pudo salir con su pretensión, defendiendo ella con gran fuerça su honestidad. Y viendo ya el maldito tirano, que era gastar tiempo en pensar de vencerla, ni pensar de mudarla de la firmeza de su propósito, quiso vengarse della, con matarla. Y ansí tornándola a atar al árbol, le puso al cuello una cinta, o talauarte, con que acabó de matar, a la que ya estaua medio muerta de los tormentos que le auía dado.

O lamentosíssimo expectáculo: $\mathrm{O}$ crueldad nunca vista, ni pensada; $\mathrm{O}$ castidad y limpieza de donzella, nunca bastantemente encarecida, ni alabada. La qual excedió con gran ventaja a la honestidad de la casta Lucrecia (por más alabada que sea su castidad por los autores que la quieren escusar del adulterio) quando la quiso deshonrar aquel hijo del Rey Tarquino, amenazándola de muerte, y de que diría a su marido Colatino, que la auía hallado con otro. En lo qual (aunque no se puede negar fuerça), se puede sospechar que consintió en la fuerça, y ansí no dexó de tener culpa, y por esso se dio la pena, que fue matarse. Lo qual largamente trata Augustino en su Cibdad de Dios. Más en esta castíssima Infanta, no ouo sospecha de culpa, pues tanto, y con tanta constancia se defendió, hasta morir en la demanda.

Después de aver cometido este tiránico sacrificio este diabólico Rey, se fue a su palacio, y estaua rebolcándose sobre vna cama con rauia mortal, donde vino la Reyna, que auía sido auisada de lo que passaua, por uno de los caualleros que venían con su hermana, que sospechando lo que podía ser fue por la huella del cauallo del Rey, al lugar del sacrificio, y lleuando en los braços la Reyna vn niño que tenía del Rey, le mató con vna daga, y se la arrojó al marido (más como no le acertasse) se baxó por ella, y se la metió por los pechos.

Este fue el fin de esta lastimosa tragedia, y lo será de la gran fuerça que tiene el amor sensual, como emos visto en clamor deste maldito Rey con la honestíssima Infanta Hera.

\section{V}

JuAn LóPEZ DE ÚBEDA, Cancionero general de la Doctrina Cristiana, Alcalá de Henares, Juan Iñiguez de Lequeriza imp., 1579.

Philomena de san Buenauentura, traduzida de Latín en Romance, y METRO VULGAR, DE PIE QUEBRADO.

Primer cántico. Quam dulcemente canta el Ruyseñor.

2 De como la Philomena o Ruyseñor muere, que es cosa de notar.

3 En que se declara, que se medita en estas horas, Maytines, Prima, Tercia, Sexta, y Nona, y Vísperas. 
4 En el que se aplica lo dicho místicamente al alma contemplatiua.

5 En que se declara el beneficio de la creación, con otras consideraciones muy deuotas.

6 Donde se toca la natiuidad del Señor, y con la presencia del niño canta el alma más affectuosamente.

7 En el cual se declara la peregrinación del Señor en el mundo, y el valor de su doctrina sagrada.

8 Donde con lágrimas la deuota alma recuenta los trabajos del Señor y su muerte, donde con desseos encendidos dessea morir con su esposo en la Cruz.

9 En que declara el autor las cosas que un alma deuota como la que aquí pintamos en muy alta contemplación, pasa al pie de la Cruz.

10 Donde el alma muere de amor, y es absorta en Dios, donde se le da firme confiança de la gloria, y de como el alma que aquí llega, esta ciega sorda y muda al mundo, y en solo Dios viue.

11 Donde se declara esta passada meditación.

12 Donde se ponen muchas alabanças desta dichosa y bienauenturada alma que mereció llegar a este punto.

\section{VI}

Diego De Ávalos, Defensa de las damas, Lima, 1603, fol. 80.

No florescio (señora) en Filomena

menos la castidad en su pureza,

pues por guardarla padesció tal pena,

de sacrílega mano con fiereza

por lo qual debe ser de olvido agena,

el mundo celebrando la aspereza,

que en su persona usó el grossero amante,

con que ella se mostró casta y constante.

Historia fue del orbe conoscida,

y al parescer de todos estimada;

de las naciones todas traduzida,

mas de nadie (qual deue) celebrada:

y pues es justo viua eterna vida,

y en lugar de nido colocada;

aquí yrá debaxo vuestro amparo,

luz que demostrará su valor claro.

Pues no le importó tanto auer nascido

en Athenas Infanta poderosa,

ni auer con su beldad resplandecido 
por fama en la región más invidiosa: ni ser del mundo todo conoscido su tormento, y la causa tan honrosa; quanto el ser ya por vos fauorescida, pues viuirá en eterna fama y vida.

No menos que la culpa de Tereo, deue ser esta gloria ponderada, el mal del uno, y bien de otro desseo, por el qual la victoria fue ganada: buele la fama de tan gran tropheo 